Giselle Margareth Pilla Blankenstein ${ }^{1}$

Arlindo Philippi Junior ${ }^{1}$

\title{
O DESCARTE DE MEDICAMENTOS E A POLÍTICA NACIONAL DE RESÍDUOS SÓLIDOS: UMA MOTIVAÇÃO PARA A REVISÃO DAS NORMAS SANITÁRIAS
}

The disposal of medicines and the Brazilian National Solid Waste Policy: A motivation for the review of health standards

${ }^{1}$ Universidade de São Paulo. São Paulo/SP, Brasil.

Correspondência: Giselle Margareth Pilla Blankenstein.E-mail: gmblankenstein@usp.br

Recebido: 30/06/2017. Aprovado: 10/10/2017. Revisado após aprovação: 27/04/2018. 


\section{RESUMO}

Medicamentos e poluentes orgânicos emergentes são contaminantes de potencial risco à saúde e ao meio ambiente, porém impedir que entrem em contato direto com a natureza é um grande desafio. A legislação pode ser compreendida como a principal ferramenta existente para mitigar o problema e, no Brasil, encontra-se em diferentes diplomas legais. $\mathrm{O}$ levantamento da legislação de abrangência nacional e de artigos científicos que versem sobre descarte de medicamentos foi realizado na internet. As resoluções da Agência Nacional de Vigilância Sanitária e do Conselho Nacional do Meio Ambiente foram as normas mais citadas nas pesquisas e apresentaram dispositivos sobre descarte nos estabelecimentos de saúde contrários à legislação federal e às pesquisas referentes a tecnologias de tratamento da água e do solo. No contexto do ordenamento jurídico brasileiro, a Política Nacional de Resíduos Sólidos (Lei n. 12.305/2010) e a Convenção de Basileia sobre o Controle dos Movimentos Transfronteiriços de Resíduos Perigosos e seu Depósito (Decreto n. 875/1993) são limitadoras do poder regulamentador da Agência e do Conselho. Dessa forma, as resoluções que atualmente regulam o descarte de medicamentos precisam ter seu texto alterado para que fiquem em conformidade com as tecnologias existentes e a legislação federal.

\section{Palavras-Chave}

Legislação Sanitária; Normas Jurídicas; Resíduos; Responsabilidade Legal; Serviços de Saúde.

\section{ABSTRACT}

Medicines and emerging organic pollutants are contaminants that carry potential health and environmental risk; preventing direct contact of these products with nature is a great challenge. Legislation can be understood as the main existing tool to mitigate the problem, and in Brazil it can be found in different legal texts. The survey of national legislation and scientific articles dealing with drug disposal was carried out on the Internet. The Brazilian Health Regulatory Agency and National Environment Council norms were the most cited in the surveys and presented articles for disposal in health facilities that are contrary to federal legislation and to research concerning water and soil treatment technologies. In the context of the Brazilian legal system, the National Solid Waste Policy (Law No. 12,305/2010) and the Basel Convention on the Control of Transboundary Movements of Hazardous Wastes and Their Disposal (Decree No. 875/1993) limit the regulatory power of the agency and the council. Therefore, resolutions currently regulating drug disposal need to be reviewed and amended to conform to existing technologies and federal legislation.

\section{Keywords}

Health Legislation; Health Services; Legal Liability; Legal Norms; Waste. 


\section{Introdução}

Medicamento é um produto farmacêutico, tecnicamente obtido ou elaborado, com finalidade profilática, curativa, paliativa ou para fins de diagnóstico ${ }^{1}$. Consumidos por animais e por pessoas de todas as classes sociais e em todas as fases da vida, os medicamentos não são totalmente absorvidos pelos metabolismos animal e humano e são liberados no meio ambiente através dos excrementos.

Evitar o contato direto desses produtos químicos com a natureza ainda é a melhor forma de evitar contaminação, pois a tecnologia utilizada para purificar solo e água - no mundo - ainda é ineficiente para livrá-los de todos os contaminantes.

Os medicamentos integram os chamados poluentes orgânicos emergentes (POE) ou contaminantes, compostos químicos presentes também em outros produtos comerciais como embalagens de alimentos, produtos de higiene, agrotóxicos, produtos veterinários etc., bem como em micro-organismos encontrados em matrizes ambientais e biológicas - os POE têm por característica a ausência de monitoramento e de legislação regulatória, apesar de seu potencial risco à saúde e ao meio ambiente ${ }^{2}$.

Se o consumo dos medicamentos obrigatoriamente significará que um percentual reduzido da dosagem será liberado ao meio ambiente, o descarte dos estoques excedentes de medicamentos, seja das empresas integrantes da cadeia logística, seja dos lares, é um desafio sanitário a ser investigado enquanto a tecnologia não avança.

A legislação pode ser compreendida como a principal ferramenta existente para mitigar o problema e, no Brasil, encontra-se em diferentes diplomas legais. Nesse sentido, conhecer a legislação - ao menos a federal, aplicada a todo o país - é o primeiro passo para compreender a forma prevista para descarte de medicamentos no Brasil e se esta previsão corresponde ao conhecimento técnico-científico existente.

O aprimoramento de ideias obtido neste levantamento classifica a pesquisa como exploratória ${ }^{3}$ e, ao final, foi confirmada a hipótese de não conformidade das normas sanitárias com o conhecimento técnico existente e com a legislação federal em vigor.

A experiência empírica norteou o levantamento documental realizado: a legislação foi encontrada em páginas oficiais da internet, com conteúdo informado pelos órgãos governamentais, e serviram de premissa para localizar estudos

\footnotetext{
${ }^{1}$ BRASIL. Lei n. 5.991, de 17 de dezembro de 1973. Dispõe sobre o controle sanitário do comércio de drogas, medicamentos, insumos farmacêuticos e correlatos, e dá outras providências. Disponível em: <http://www. planalto.gov.br/ccivil_03/Leis/L5991.htm>. Acesso em: 27 mar. 2013.

${ }^{2}$ SILVA, C. G. A.; COLLINS, C. H. Aplicações de cromatografia líquida de alta eficiência para o estudo de poluentes orgânicos emergentes. Química Nova, Campinas, v. 34, n. 4, p. 665-676, 2011. Disponível em: <http://unicamp.sibi.usp.br/unicamp/bitstream/handle/SBURI/23903/S0100-40422011000400020. pdf?sequence=1>. Acesso em: 01 mar. 17. http://dx.doi.org/10.1590/S0100-40422011000400020.

${ }^{3} \mathrm{GIL}$, A. C. Métodos e técnicas de pesquisa social. São Paulo: Atlas, 2007.
} 
científicos e notícias não científicas relacionados ao descarte de medicamentos. O método utilizado nesta etapa da pesquisa foi o indutivo, pois, conforme ensinam Marconi e Lakatos, a indução "é um processo mental por intermédio do qual, partindo de dados particulares, suficientemente constatados, infere-se uma vontade geral ou universal, não contida nas partes examinadas"4.

Na leitura do material levantado, por sua vez, utilizou-se o método dialético para interpretação do conteúdo, pois esse método compreende processos, interdependência, transformação, interpretação dos contrários e sua análise qualitativa ${ }^{5}$.

\section{Objetivos e procedimento metodológico}

Compreender de qual forma está previsto o descarte de medicamentos na legislação brasileira e se esta previsão corresponde ao conhecimento técnico-científico existente são os objetivos desta pesquisa.

As hipóteses trabalhadas são as de que as normas sanitárias não acompanharam o avanço tecnológico e estão em desconformidade com a legislação federal, ambas confirmadas com a análise dos dados.

O procedimento metodológico consistiu no levantamento da legislação de abrangência nacional referente ao descarte de medicamentos em páginas do governo federal na internet: < planalto.gov.br $>$; $<$ bvsms.saude.gov.br $>$; $<$ mma.gov. br $>$; e $<$ lexml.gov.br $>$.

Após a leitura da legislação federal, foi feito levantamento de artigos científicos, localizando-os a partir do nome das normas encontradas, de seus respectivos números e das palavras "resíduos", "medicamento" e "logística reversa" isoladamente em todos os campos de pesquisa disponíveis na base Scientific Electronic Library Online (Scielo) e na Biblioteca Digital de Teses e Dissertações da Universidade de São Paulo. As mesmas palavras utilizadas na Scielo foram utilizadas aos pares, em português e inglês, na ferramenta de busca Google, em que foram selecionadas notícias além de textos técnicos.

\section{O sistema legislativo: noções}

O ordenamento jurídico pode ser compreendido como as normas incidentes em um determinado território, para as pessoas que nele estejam ou que a ele estejam vinculadas. A figura mais próxima para explicá-lo talvez seja a de um pião ${ }^{6}$ rodando: o brinquedo infantil mantém-se em movimento de rotação por inércia,

\footnotetext{
${ }^{4}$ MARCONI, M. A., LAKATOS, E. M. Fundamentos de metodologia científica. 6. ed. São Paulo: Atlas, 2009. p. 86. ${ }^{5}$ Id. Ibid.

${ }^{6}$ Nos manuais tradicionais de Direito, a figura apresentada é de uma pirâmide, estática, formada por uma hierarquia de leis, a mais importante no topo.
} 
girando no eixo vertical. É o ponto mínimo de contato com o solo que garante a duração de seu movimento.

No pião do ordenamento jurídico, a Constituição da República ${ }^{7}$ (Constituição) é esse ponto mínimo de contato no chão que mantém sua dinâmica. Para quem está de fora, é difícil identificar as mudanças, qual direção irá tomar, seu movimento interno, o que realmente é material (pião/lei) e o que é ilusão de ótica (convenções sociais), porém, para quem integra o conjunto, a pressão vertical é percebida. Havendo dúvida, o pião balança e o Supremo Tribunal Federal é provocado a intervir, indicando a direção da Constituição.

A conformidade com a Constituição é condição para a existência de uma norma no ordenamento jurídico, portanto não basta sua publicação do Diário Oficial. E há regras não escritas, obedecidas pela sociedade. Se as regras da sociedade contrariarem a Constituição ou se as existentes não forem respeitadas, a presença de grande movimentação interna ou de intervenção externa desestabiliza a Constituição; o ordenamento jurídico cai e novo ordenamento, com nova Constituição, precisará ser elaborado.

Na Constituição brasileira promulgada em 1988 (CF/1988), o artigo 59 dispõe sobre as normas existentes no ordenamento jurídico brasileiro: "Art. 59. O processo legislativo compreende a elaboração de: I - emendas à Constituição; II - leis complementares; III - leis ordinárias; IV - leis delegadas; V - medidas provisórias; VI - decretos legislativos; VII - resoluções.” A ordem dos incisos é interpretada como seu posicionamento hierárquico, geralmente justificado pela matéria objeto do diploma legal e/ou quórum de aprovação necessário.

Mesmo com a estrutura organizada, há situações em que não é possível ter certeza de qual é a lei aplicável, o que é chamado de "lacuna da lei". A lacuna pode ocorrer porque não é encontrada uma regulamentação específica para o assunto situação cada vez mais comum com o dinamismo da tecnologia e da sociedade - ou porque há mais de uma lei regulando (antinomia $)^{8}$.

Quando não há clareza da regra, é possível construir uma interpretação jurídica a partir das regras de hermenêutica jurídica, respeitando a hierarquia e o momento em que cada norma entrou em vigor.

Resumidamente, é possível afirmar que hermenêutica jurídica é a técnica de interpretar o direito que, por sua vez, é o conjunto de regras (escritas e não escritas)

\footnotetext{
${ }^{7}$ BRASIL. Constituição da República Federativa do Brasil de 1988. Disponível em: <http://www.planalto.gov. br/ccivil_03/constituicao/constituicao.htm >. Acesso em: 27 mar. 2017.

8“Art. 4: Quando a lei foi omissa, o juiz decidirá o caso de acordo com a analogia, os costumes e os princípios gerais de direito." BRASIL. Decreto Lei n. 4657, de 4 de setembro de 1942. Lei de introdução às normas do direito brasileiro. Disponível em: <http://www.planalto.gov.br/ccivil_03/decreto-lei/Del4657.htm>. Acesso em: 07 maio 2017.
} 
para uma determinada sociedade, em determinado período e em um determinado território. Isso significa que pode haver divergência entre as normas brasileiras e as de outros países, entre as normas dos Estados brasileiros e entre as normas dos municípios - motivo pelo qual é importante conferir periodicamente qual texto está atualizado.

As pesquisas interdisciplinares costumam adotar exclusivamente a interpretação literal da norma, ou seja, leem o que está escrito em um texto sem considerar o contexto. É válido mencionar que no Brasil, para interpretar uma regra, duas verificações prévias são necessárias: (a) confirmar se quem editou a lei tinha competência para fazê-lo e se o fez seguindo o procedimento legal para o diploma correspondente; (b) a posição da lei dentro do ordenamento jurídico quanto a sua posição hierárquica e quanto ao tempo (data) em que foi publicada, para ter certeza se ainda está vigendo, pois o pião ordenamento jurídico está em constante movimento.

Essas duas verificações prévias à interpretação da lei são encontradas na Constituição. Conforme já dito, a Constituição é a norma mais importante de um ordenamento jurídico e, por isso, a base de toda e qualquer hermenêutica jurídica. No Brasil, nenhum texto ou interpretação pode contrariá-la. A competência, a definição de quem tem legitimidade para legislar sobre determinada matéria (se União, estados ou municípios), consta nos artigos da Constituição.

Quanto ao descarte de medicamentos, o assunto é complexo e permite ser enquadrado em diferentes matérias de competência comum (União, estados e municípios podem simultaneamente regular). Formalmente, é preciso analisar o caso concreto para determinar se a competência é privativa (delegável) ou concorrente (um ente federativo suplementa o que o outro não regulou).

As normas vigentes antes da Constituição - e que possuíam conteúdo diverso a ela - deixaram de viger a partir da sua promulgação. A revogação ocorre mesmo que não haja texto indicando-a, ou seja, não precisa ser expressa, pode ser tácita (a interpretação leva à conclusão de que o texto está revogado). Se ocorrer de alguma lei posterior à Constituição ser contrária a seu conteúdo e houver divergência quanto a esse entendimento, é possível recorrer ao Poder Judiciário para que tal lei posterior não surta efeitos.

Na ação judicial, o Poder Judiciário faz análise formal e análise material. A análise formal engloba verificar se os requisitos legais de tramitação foram respeitados: formalmente, há um quórum exigido para aprovação da lei, o qual varia conforme a matéria regulada ou quem a propõe; antes da publicação de um texto normativo, há um trâmite entre os poderes Legislativo e Executivo que insere a lei aprovada em uma relação hierárquica quanto às demais normas do ordenamento jurídico. A análise material, por sua vez, analisa o conteúdo das normas: se foi enquadrado corretamente ou se diverge de alguma lei vigente, por exemplo. 
Sempre que houver omissão da lei, é possível, ainda, regular a matéria mediante ato administrativo. Na área da saúde, são exemplos de atos administrativos a Instrução Normativa (IN) da Agência Nacional de Vigilância Sanitária (Anvisa) e a Resolução da Diretoria Colegiada (RDC) da Anvisa. Formalmente, IN e RDC são atos administrativos que existem para orientar as pessoas subordinadas ao órgão que as editou - e, por isso, sequer constam na relação do artigo 59 da CF/1988. Contudo, a ausência de norma regulando determinada matéria eleva o status do ato administrativo e, na hierarquia do sistema jurídico, ele passa a ser materialmente considerado como lei (embora formalmente continue sendo ato administrativo).

Na prática, os funcionários do órgão emissor do ato administrativo (incluindo seus fiscais) estão a ele vinculados, ou seja, o órgão fiscalizador edita atos administrativos determinando os critérios de análise e os procedimentos que todos os envolvidos na administração pública daquele setor precisam respeitar. São essas pessoas que dirão se uma licença será emitida ou se uma multa será aplicada, e fazem isso seguindo a orientação a quem são subordinadas. As medidas administrativas questionáveis face à Constituição e à legislação infraconstitucional, em tese, poderiam ser contraditadas pelo servidor público a sua chefia, mas na prática o encargo fica para o cidadão.

Cabe ao Poder Judiciário, quando provocado, decidir se determinado procedimento está correto ou se uma exigência legal pode limitar um direito ou exigir uma ação/omissão. O processo judicial é moroso e, não raro, após proferida a decisão, é emitida nova lei ou ato administrativo em sentido desfavorável a quem ganhou a ação judicial (fato que poderá provocar nova discussão do assunto decidido).

Dessa forma, não surpreende que as pesquisas na área da saúde restrinjam o levantamento da legislação aos textos das regulamentações específicas da saúde, sem levantar a discussão se seu conteúdo possui coerência com os avanços tecnológicos ou com as melhores práticas.

Essa dinâmica faz com que, tanto no conhecimento acadêmico quanto na prática profissional, o ato administrativo prevaleça à Constituição e somente por meio de processo judicial (medida custosa financeira e politicamente) o cidadão consiga fazer com que lei hierarquicamente superior - e até a Constituição - seja aplicada.

Uma expressão cada vez mais utilizada que ilustra o relatado é a judicialização da saúde, movimento de pacientes inconformados com as limitações impostas por decisões administrativas e que recorrem ao Poder Judiciário para que a Constituição seja cumprida e, consequentemente, o tratamento médico ou medicamento seja disponibilizado de forma gratuita. A saúde garantida como direito social no artigo $6^{\circ} \mathrm{da} C F / 1988$, no entanto, inclui também a existência de "políticas sociais e econômicas que visem à redução do risco de doença e de outros agravos", não apenas tratamento médico alopático.

A CF/1988, dessa forma, prevê que haja políticas tais como as que proíbam o descarte de POE diretamente na natureza. 


\section{Descarte de medicamentos na legislação federal}

O artigo 225 da CF/1988 declara que não há acesso a uma sadia qualidade de vida sem que o meio ambiente esteja ecologicamente equilibrado. Há, dessa forma, o reconhecimento de uma limitação dos recursos naturais e da importância da natureza para a vida humana, sendo possível afirmar que o texto constitucional prevê intrínseca relação entre saúde e meio ambiente. A principal visualização de meio ambiente desequilibrado é a presença de resíduos e rejeitos: em local sujo e contaminado, não existe vida com saúde.

A Lei n. 12.305/2010 instituiu a Política Nacional de Resíduos Sólidos (PNRS), que regula os resíduos gerados no Brasil exceto os rejeitos radioativos (art. $\left.1^{\circ}, \S 2^{\circ}\right)$. O artigo $3^{\circ}$ contém dois conceitos que esclarecem seu alcance:

XV - rejeitos: resíduos sólidos que, depois de esgotadas todas as
possibilidades de tratamento e recuperação por processos tecnoló-
gicos disponíveis e economicamente viáveis, não apresentem outra
possibilidade que não a disposição final ambientalmente adequada;
XVI - resíduos sólidos: material, substância, objeto ou bem des-
cartado resultante de atividades humanas em sociedade, a cuja
destinação final se procede, se propõe proceder ou se está obri-
gado a proceder, nos estados sólidos ou semissólidos, bem como
gases contidos em recipientes e líquidos cujas particularidades
tornem inviável o seu lançamento na rede pública de esgotos ou
em corpos d'água, ou exijam para isso soluções técnica ou eco-
nomicamente inviáveis em face da melhor tecnologia disponível';

As definições transcritas demonstram que medicamentos são considerados resíduos sólidos ou rejeitos pela PNRS. A classificação de resíduos na PNRS é feita quanto à origem e à periculosidade, mas tal classificação não interfere na aplicação da PNRS; seus princípios e ferramentas devem ser utilizados em todos os resíduos, sendo prioritário seguir a ordem do artigo $7^{\circ}$ : não geração, redução, reutilização, reciclagem e tratamento dos resíduos sólidos, bem como disposição final ambientalmente adequada dos rejeitos. No mesmo diploma consta, ainda, que o gerador direto ou indireto de resíduo (pessoa física ou jurídica, de direito público ou privado) é responsável por seu gerenciamento, que deve ocorrer de acordo com os princípios e instrumentos previstos na PNRS.

São exemplos de objetivos da PNRS a diminuição do volume de resíduos e a geração de riqueza a partir deles. À medida que a tecnologia for evoluindo, os

\footnotetext{
9BRASIL. Lei 12.305, de 2 de agosto de 2010. Institui a Política Nacional de Resíduos Sólidos; altera a Lei $n^{\circ}$ 9.605, de 12 de fevereiro de 1998; e dá outras providências. Disponível em: <http://www.planalto.gov. br/ccivil_03/_ato2007-2010/2010/lei/l12305.htm>. Acesso em: 27 mar. 2017. O Decreto n. 7.404/2010 regulamenta a PNRS prevendo que "a responsabilidade compartilhada será implementada de forma individualizada e encadeada” (art. $5^{\circ}$, parágrafo único). 0 decreto trata dos instrumentos da PNRS: logística reversa, coleta seletiva, acordos setoriais, bem como a participação dos catadores. Não há menção direta aos resíduos de saúde, apenas a previsão da existência de cadastro nacional de operadores de resíduos perigosos (CNORP), regulado pela Instrução Normativa n. 01/2013 do Instituto do Meio Ambiente (Ibama).
} 
parâmetros de exigência serão adaptados. A PNRS prevê também instrumentos para sua efetivação, dentre eles os acordos setoriais (art. $\left.8^{\circ}, \mathrm{XVI}\right)$.

O acordo setorial é um contrato entre poder público e a cadeia logística de suprimentos de um determinado produto e é obrigatório a alguns setores, nos termos dos artigos 33 e $34^{10}$ da PNRS. Seu conteúdo procura viabilizar o descarte ambientalmente adequado. As Tabelas 1 e 2 listam os projetos de lei em trâmite no Congresso Nacional ${ }^{11}$ que têm por objeto regular o descarte de medicamentos, muitos incluindo-os na lista de acordo setorial obrigatório.

O fundamento para a existência do acordo setorial é a responsabilidade compartilhada pelo ciclo de vida do produto, que já é exigível individualmente. $\mathrm{O}$ acordo setorial permite uma construção coletiva dos papéis a serem assumidos por cada ente da cadeia de suprimentos, para que possam agir de forma integrada.

É possível firmar acordo setorial sem que ele esteja previsto em lei como obrigatório. Por esse motivo, em 10 de outubro de 2013, foi publicado pela Secretaria de Recursos Hídricos e Ambiente Urbano extrato de edital de chamamento de fabricantes, importadores, distribuidores e comerciantes de medicamentos para elaboração de Acordo Setorial para a implantação de Sistema de Logística Reversa de Medicamentos ${ }^{12}$.

Prorrogado uma vez o prazo para envio de proposta, dez foram apresentadas e quatro foram consideradas elegíveis, porém nenhum acordo foi formalizado. A natureza contratual do acordo setorial pressupõe negociação - e negociação é processo que, se não for exigido prazo para conclusão, como ocorre com os acordos setoriais previstos na PNRS, pode ser estendido tanto quanto as partes envolvidas quiserem (ou não tiverem interesse em definir responsabilidades).

Só a definição de quantos acordos setoriais existirão ou a abrangência territorial de cada um é suficiente para que nenhum acordo seja firmado. E a existência de mais de um acordo é prevista em lei (art. 34) e factível tendo em vista a diversidade de realidades do Brasil; difícil imaginar que uma única solução atenda de forma satisfatória a todo território nacional e a empresas de diferentes portes.

Em relação aos medicamentos e seu descarte, além da PNRS, em 1993, o Decreto n. $875 / 1993^{13}$ internalizou a Convenção de Basileia sobre o Controle dos

\footnotetext{
${ }^{10}$ Agrotóxicos, pilhas, baterias, pneus, óleos lubrificantes, lâmpadas fluorescentes, de vapor de sódio e mercúrio e de luz mista e produtos eletroeletrônicos e seus componentes. Nos agrotóxicos e óleos lubrificantes há também previsão de recolhimento de suas embalagens.

${ }^{11}$ Pesquisa realizada em 28 de julho de 2017, na Rede de Informação Legislativa e Jurídica (Lexml), portal de buscas do governo federal; o termo de busca utilizado foi "descarte medicamento".

${ }^{12}$ BRASIL. SECRETARIA DE RECURSOS HÍDRICOS E AMBIENTE URBANO. Edital de chamamento para implantação de sistema de logística reversa. Diário Oficial da União. Seção 3, Brasilia, 10 out. 2013, n. 197, p. 175.

${ }^{13}$ BRASIL. Decreto n. 875, de 19 de julho de 1993. Promulga o texto da Convenção sobre o Controle de Movimentos Transfronteiriços de Resíduos Perigosos e seu Depósito. Disponível em: <http://www.planalto. gov.br/ccivil_03/decreto/d0875.htm>. Acesso em: 14 jun. 2018.
} 
Tabela 1. Projetos de lei em trâmite na Câmara dos Deputados

\begin{tabular}{|c|c|}
\hline N. do PL & Tema tratado pelo PL \\
\hline $595 / 2011$ & $\begin{array}{l}\text { Acrescenta o artigo } 6 \text { à Lei n. 5.991/1973, para dispor sobre o recolhimento e o } \\
\text { descarte consciente de medicamentos. }\end{array}$ \\
\hline $2.121 / 2011$ & $\begin{array}{l}\text { Dispõe sobre o descarte de medicamentos vencidos ou impróprios para consumo } \\
\text { nas farmácias e drogarias e dá outras providências. }\end{array}$ \\
\hline $2.148 / 2011$ & $\begin{array}{l}\text { Torna obrigatória a criação de pontos de coleta para recolhimento de resíduos de } \\
\text { medicamentos nas farmácias e drogarias. Apensado ao PL 2121/2011. }\end{array}$ \\
\hline $2.494 / 2011$ & $\begin{array}{l}\text { Torna obrigatória a criação de pontos de coleta para recolhimento de resíduos de } \\
\text { medicamentos nos condomínios residenciais, resorts, hotéis e pousadas. Apensado } \\
\text { ao PL } 2121 / 2011 \text {. }\end{array}$ \\
\hline $5.705 / 2013$ & $\begin{array}{l}\text { Dispõe sobre a participação de farmácias, drogarias e laboratórios farmacêuticos no } \\
\text { descarte e na destinação final de medicamentos vencidos ou impróprios para o consumo, } \\
\text { em todo o território nacional, e dá outras providências. Apensado ao PL 2121/2011. }\end{array}$ \\
\hline $6.160 / 2013$ & $\begin{array}{l}\text { Altera a Lei n. 12.305/2010 que institui a Política Nacional de Resíduos Sólidos, incluindo os } \\
\text { medicamentos para uso humano e animal, seus resíduos e embalagens entre os materiais } \\
\text { a serem submetidos ao sistema de logística reversa. Apensado ao PL 2121/2011. }\end{array}$ \\
\hline $7.064 / 2014$ & $\begin{array}{l}\text { Dispõe sobre o recolhimento de medicamentos vencidos e a devolução de medicamentos } \\
\text { excedentes ainda em validade, e dá outras providências. Apensado ao PL 2121/2011. }\end{array}$ \\
\hline $8.278 / 2014$ & $\begin{array}{l}\text { Dispõe sobre a participação de farmácias, drogarias e laboratórios farmacêuticos no } \\
\text { descarte e na destinação final de medicamentos vencidos ou impróprios para o consumo, } \\
\text { em todo o território nacional, e dá outras providências. Apensado ao PL 2121/2011. }\end{array}$ \\
\hline $893 / 2015$ & $\begin{array}{l}\text { Altera a Lei n. } 12.305 / 2010 \text {, para dispor sobre descarte de medicamentos, produtos } \\
\text { médicos e produtos para diagnóstico de uso in vitro. Apensado ao PL 2121/2011. }\end{array}$ \\
\hline $1.109 / 2015$ & $\begin{array}{l}\text { Institui a Política Nacional de Resíduos Sólidos a fim de proibir o encaminhamento } \\
\text { de resíduos de serviços de saúde para a disposição final sem tratamento específico. } \\
\text { Apensado ao PL 2121/2011. }\end{array}$ \\
\hline $2.674 / 2015$ & $\begin{array}{l}\text { Altera o Decreto Lei n. } 467 / 1969 \text { e a Lei n. } 12.305 / 2010 \text {, para determinar o } \\
\text { recolhimento de produtos de uso veterinário, seus resíduos e embalagens e incluí-los } \\
\text { entre os itens sujeitos à logística reversa. Apensado ao PL 2121/2011. }\end{array}$ \\
\hline PL 5152/16 & $\begin{array}{l}\text { Dispõe sobre responsabilidade pela destinação final de medicamentos, drogas, } \\
\text { consumos farmacêuticos, correlatos, cosméticos e saneantes deteriorados ou com } \\
\text { prazo de validade expirado. Apensado ao PL } 2121 / 2011 \text {. }\end{array}$ \\
\hline $6.776 / 2016$ & $\begin{array}{l}\text { Institui o programa de destinação dos medicamentos vencidos. } \\
\text { Apensado ao PL 2121/2011. }\end{array}$ \\
\hline
\end{tabular}

Fonte: Autores

Movimentos Transfronteiriços de Resíduos Perigosos e seu Depósito. Nessa convenção, os países signatários reconhecem que deve haver controle do fluxo de resíduos perigosos. Constam na lista de substâncias a serem controladas os resíduos de medicamentos e produtos farmacêuticos, resíduos oriundos da produção e preparação de produtos farmacêuticos e resíduos oriundos da produção, formulação e utilização de produtos fitofarmacêuticos e, por isso, estão regulados pela referida convenção.

O texto da convenção foi aprovado na íntegra pelo Brasil, porém ficou expressa no decreto de internalização a preocupação ante às deficiências da 
Tabela 2. Projetos de lei em trâmite no Senado Federal

\begin{tabular}{|c|c|}
\hline N. do PL & Tema tratado pelo PL \\
\hline $710 / 2007$ & $\begin{array}{l}\text { Altera a Lei n. 5991/1973, para obrigar farmácias e drogarias a manter serviço } \\
\text { de atendimento ao público para o recebimento de medicamentos para descarte. } \\
\text { Arquivado no final da legislatura. }\end{array}$ \\
\hline $229 / 2010$ & $\begin{array}{l}\text { Inclui art. } 27-A \text { na Lei n. } 12.305 / 2010 \text {, para transferir ao Município a } \\
\text { responsabilidade pela coleta e pela destinação final adequada do lixo hospitalar. } \\
\text { Arquivado no final da legislatura. }\end{array}$ \\
\hline $148 / 2011$ & $\begin{array}{l}\text { Altera a Lei n. } 12.305 / 2010, \text { para disciplinar o descarte de medicamentos de uso } \\
\text { humano ou de uso veterinário. }\end{array}$ \\
\hline $403 / 2014$ & $\begin{array}{l}\text { Altera as Leis n. } 12.546 / 2011, \text { n. } 12.375 / 2010 \text { e n. } 9.249 / 1995 \text {, para instituir } \\
\text { medidas de desoneração tributária de atividades relacionadas à logística reversa de } \\
\text { que trata a Lei n. } 12.305 / 2010 \text {. }\end{array}$ \\
\hline $375 / 2016$ & $\begin{array}{l}\text { Altera as Leis n. } 12.305 / 2010 \text { e n. } 9.605 / 1998 \text {; e dá outras providências, para } \\
\text { inserir medicamentos de uso humano e suas embalagens no rol de produtos para } \\
\text { os quais é obrigatória a implementação de sistema de logística reversa. }\end{array}$ \\
\hline
\end{tabular}

Fonte: autores

convenção em apontar solução para o problema da crescente geração de resíduo e para um controle mais rigoroso de sua movimentação.

Aderindo à convenção, os países signatários assumem o compromisso de minimizar a quantidade e o conteúdo tóxico desses resíduos perigosos gerados, bem como assegurar sua disposição ambientalmente saudável.

\section{Artigo 4}

2. Cada Parte deverá tomar medidas adequadas para:

(a) Assegurar que a geração de resíduos perigosos e outros resíduos em seu território seja reduzida a um mínimo, levando em consideração aspectos sociais, tecnológicos e econômicos;

(c) Assegurar que as pessoas envolvidas na administração de resíduos perigosos e outros resíduos dentro de seu território tomem as medidas necessárias para evitar a poluição por resíduos perigosos e outros resíduos provocada por essa administração e, se tal poluição ocorrer, para minimizar suas consequências em relação à saúde humana e ao meio ambiente; ${ }^{14}$

No decreto consta, ainda, que os produtos listados só podem ser exportados para locais com tratamento adequado e se houver expresso consentimento da autoridade local em importá-lo. O risco à saúde humana e ao meio ambiente proveniente desses resíduos é reiterado no decorrer do texto. Dessa forma, é possível afirmar que a PNRS reitera o compromisso assumido internacionalmente pelo Brasil.

${ }^{14}$ BRASIL. Decreto n. 875, de 19 de julho de 1993, cit. 
Merecem destaque também os seguintes dispositivos da Convenção:

As Partes da presente Convenção, [...]

Conscientes da necessidade de continuar o desenvolvimento e a implementação de tecnologias ambientalmente racionais, que gerem escassos resíduos, medidas de reciclagem e bons sistemas da administração e de manejo, permitam reduzir ao mínimo a geração de resíduos perigosos e outros resíduos;

[...]

13. As Partes deverão rever periodicamente as possibilidades de reduzir a quantidade e/ou o potencial de poluição dos resíduos perigosos e outros resíduos que são exportados para outros Estados, particularmente para os países em desenvolvimento.

[...]

Os riscos potenciais de determinados tipos de resíduos ainda não foram completamente documentados; não existem testes para definir quantitativamente esses riscos. É necessário aprofundar as pesquisas a fim de desenvolver meios para caracterizar riscos desses resíduos em relação ao ser humano e/ou ao meio ambiente.

Os dispositivos da PNRS e da Convenção de Basileia são complementares, porém, sempre que houver omissão ou dúvida na interpretação da lei (neste caso, a PNRS e a Convenção de Basileia), cabe regulamentação na esfera administrativa. A Anvisa e o Conselho Nacional do Meio Ambiente (Conama) classificam o medicamento a ser descartado como resíduo de serviço de saúde (RSS) ${ }^{15}$ e, quanto a seu descarte, estão vigentes os seguintes atos administrativos:

(i) RDC n. 306, de 7 de dezembro de 2004, que dispõe sobre o regulamento técnico para o gerenciamento de resíduos de serviços de saúde ${ }^{16}$ (a RDC n. 222, de 28 de março de 2018, substituirá a RDC n. 306/2004 a partir de 25 de setembro de 2018) ${ }^{17}$;

(ii) RDC n. 358, de 4 de maio de 2005, que dispõe sobre o tratamento e a disposição final dos resíduos dos serviços de saúde ${ }^{18}$;

\footnotetext{
${ }^{15}$ Por delegação da PNRS, Conama e Anvisa classificam os RSS em cinco grupos: Grupo A - resíduos biológicos; Grupo B - resíduos químicos; Grupo C - rejeitos radioativos; Grupo D - resíduos comuns e Grupo E - resíduos perfurocortantes. O medicamento integra o Grupo B, porém, sua embalagem - se não estiver contaminada - integra o Grupo D.

${ }^{16}$ AGÊNCIA NACIONAL DE VIGILÂNCIASANITÁRIA - ANVISA. Resolução RDCn. 306, de 10 de dezembro de 2004. Dispõe sobre o Regulamento Técnico para o gerenciamento de resíduos de serviços de saúde. Disponível em: <http://bvsms. saude.gov.br/bvs/saudelegis/anvisa/2004/res0306_07_12_2004.html>. Acesso em: 06 maio 2017.

${ }^{17}$ AGÊNCIA NACIONAL DE VIGILÂNCIA SANITÁRIA - ANVISA. Resolução RDC n. 222, de 28 de março de 2018. Regulamenta as Boas Práticas de Gerenciamento dos Resíduos de Serviços de Saúde e dá outras providências. Disponível em: <http://bvsms.saude.gov.br/bvs/saudelegis/anvisa/2018/ rdc0222_28_03_2018.pdf>. Acesso em: 23 abr. 2018.

${ }^{18}$ BRASIL. CONSELHO NACIONAL DO MEIO AMBIENTE - CONAMA. Resolução n. 358, de 29 de abril de 2005. Dispõe sobre o tratamento e a disposição final dos resíduos dos serviços de saúde e dá outras providências. Disponível em: <www.mma.gov.br/port/conama/legiabre.cfm?codlegi=462>. Acesso em: 02 abr. 2017.
} 
(iii) RDC n. 44, de 17 de agosto de 2009, que dispõe sobre boas práticas farmacêuticas para o controle sanitário do funcionamento, da dispensação e da comercialização de produtos e da prestação de serviços farmacêuticos em farmácias e drogarias ${ }^{19}$;

(iv)RDC n. 63, de 25 de novembro de 2011, que dispõe sobre os requisitos de boas práticas de funcionamento para os serviços de saúde ${ }^{20}$.

A Resolução Conama n. 358/2005, no artigo 2º inciso X, define RSS como os resíduos resultantes de atividades exercidas nos serviços relacionados com o atendimento à saúde humana ou animal, drogarias e farmácias, dentre outros serviços não relacionados diretamente com medicamentos. Essa definição é repetida na RDC n. 306/2004. A RDC n. 222/2018 conceitua os grupos de RSS (art. $3^{\circ}$, LIV a LVIII) sem conceituar RSS.

Estabelece o Conama que serão considerados RSS os resíduos que, por suas características, necessitam de processos diferenciados em seu manejo, exigindo ou não tratamento prévio a sua disposição final ${ }^{21}$. A Anvisa restringe o conceito do Conama ao local onde o resíduo é gerado; somente pode ser considerado RSS o resíduo com origem em estabelecimento de saúde (apêndice VIII da RDC n. 306/2004).

A RDC n. 222/2018 não menciona o conceito de estabelecimento de saúde, mas o de unidade geradora de resíduos de serviço de saúde, conceituada como "unidade funcional dentro do serviço no qual é gerado o resíduo". O conceito de gerador de RSS também foi alterado pela RDC n. 222/2018: não constam mais no rol de atividades o serviço relacionado ao trabalho de campo nem os produtores de materiais e controles para diagnóstico in vitro (mantendo-se seus distribuidores), e são acrescentados os salões de beleza e estética, "dentre outros afins". ${ }^{22}$

Na RDC n. 63/2011, serviço de saúde é o estabelecimento de saúde destinado a prestar assistência à população na prevenção de doenças, no tratamento, na recuperação e na reabilitação de pacientes.

A PNRS, em seu artigo 13, alínea "g”, delega aos órgãos do Sistema Nacional de Meio Ambiente (Sisnama), ao Conama, ao Sistema Nacional de Vigilância Sanitária (SNVS) e à Anvisa a definição de resíduos de serviços de saúde. A definição do Conama estabelece uma única regra: a de que medicamentos são RSS. Já

${ }^{19}$ AGÊNCIA NACIONAL DE VIGILÂNCIA SANITÁRIA - ANVISA. Resolução RDC n. 44, de 18 de agosto de 2009. Dispõe sobre Boas Práticas Farmacêuticas para o controle sanitário do funcionamento, da dispensação e da comercialização de produtos e da prestação de serviços farmacêuticos em farmácias e drogarias e dá outras providências. Disponível em: <http://bvsms.saude.gov.br/bvs/saudelegis/anvisa/2009/ res0044_17_08_2009.html>. Acesso em: 06 maio 2017.

${ }^{20}$ AGÊNCIA NACIONAL DE VIGILÂNCIA SANITÁRIA - ANVISA. Resolução RDC n. 63, de 25 de novembro de 2011. Dispõe sobre os Requisitos de Boas Práticas de Funcionamento para os Serviços de Saúde. Disponível em: <http://bvsms.saude.gov.br/bvs/saudelegis/anvisa/2011/res0063_24_11_2011.html>. Acesso em: 06 maio 2017.

${ }^{21}$ BRASIL. CONSELHO NACIONAL DO MEIO AMBIENTE. Resolução n. 358, de 29 de abril de 2005, cit.

${ }^{22}$ AGÊNCIA NACIONAL DE VIGILÂNCIA SANITÁRIA. Resolução RDC n. 222, de 28 de março de 2018, cit. 
a definição da Anvisa permite que os medicamentos descartados por famílias no ambiente doméstico não sejam considerados RSS.

Bellan et al., ao analisarem a legislação brasileira quanto ao descarte doméstico, distinguem-no dos RSS:

As sobras de medicamentos oriundas do desuso ou da expiração do prazo de validade que constam nos domicílios da população, normalmente, são destinadas diretamente para o lixo comum, rede de esgoto ou, em alguns casos, devolvidas para a rede pública. Sobre essas sobras, ainda não há legislação específica que regulamenta e orienta sobre a manipulação e destinação correta do descarte dos resíduos de medicamentos. Entretanto, sobre os resíduos sólidos de serviços de saúde já se possuem regulamentações definidas ${ }^{23}$.

A contaminação potencial de um medicamento em estabelecimentos de saúde ou em domicílios, no entanto, não difere; o volume descartado domesticamente em cidades com alta densidade demográfica pode ser, inclusive, maior que o de estabelecimentos de pequeno porte. Em qualquer classificação que seja atribuída, para respeitar o previsto na PNRS, deve-se evitar a geração de resíduos de medicamentos e, quando houver, seu descarte precisa ocorrer da forma adequada, de forma a tornar o produto inerte. A Convenção de Basileia também não faz qualquer distinção de periculosidade do medicamento devido a sua origem. Quanto à regra de descarte dos medicamentos, dispõe a RDC n. 306/2004:

11.19 - Os resíduos de produtos ou de insumos farmacêuticos que, em função de seu princípio ativo e forma farmacêutica, não oferecem risco à saúde e ao meio ambiente conforme definido no item 3.1, quando descartados por serviços assistenciais de saúde, farmácias, drogarias e distribuidores de medicamentos ou apreendidos, devem atender ao disposto no item 11.18.

3.1 - Os detentores de registro de medicamentos devem ainda manter atualizada, junto à Gerência Geral de Medicamentos/ GGMED/ANVISA, listagem de seus produtos que, em função de seu princípio ativo e forma farmacêutica, não oferecem risco de manejo e disposição final. Devem informar o nome comercial, o princípio ativo, a forma farmacêutica e o respectivo registro do produto. Essa listagem ficará disponível no endereço eletrônico da ANVISA, para consulta dos geradores de resíduos ${ }^{24}$.

\footnotetext{
${ }^{23}$ BELLAN, N. et al. Critical analysis of the regulations regarding the disposal of medication waste. Brazilian Journal of Pharmaceutical Sciences. São Paulo, v. 48, n. 3, p. 507, July/Sept. 2012. Disponível em: <http:// www.scielo.br/pdf/bjps/v48n3/a18v48n3.pdf>. http://dx.doi.org/10.1590/S1984-82502012000300018. ${ }^{24}$ AGÊNCIA NACIONAL DE VIGILÂNCIA SANITÁRIA - ANVISA. Resolução RDC n. 306, de 10 de dezembro de 2004 , cit.
} 
A Anvisa foi consultada quanto à listagem da qual trata o item 3.1 e informou, em 20 de abril de 2017, que "essa lista não foi feita por problemas operacionais e a RDC n. 306 de 2004 está em processo de revisão e a nova norma não trará mais esse item"25. E, se tivesse existido, teria contrariado a Convenção da Basileia: todos os medicamentos são substâncias com periculosidade. Assim dizem as pesquisas científicas e assim diz a legislação federal.

A redação do artigo 40 da $\mathrm{RDC}$ n. 222/2018, no entanto, manteve a possibilidade de interpretação contrária ao reconhecimento brasileiro da periculosidade dos medicamentos ao determinar que "os RSS que não apresentam risco biológico, químico ou radiológico podem ser encaminhados para reciclagem, recuperação, reutilização, compostagem, aproveitamento energético ou logística reversa"26.

Outras normas de abrangência nacional referentes ao descarte de medicamentos são da Associação Brasileira de Normas Técnicas (ABNT): a ABNT NBR 10004:2004 e a ABNT NBR 16457:2016, que regulamentam respectivamente a classificação de resíduos e o procedimento da logística reversa de medicamentos descartados pelo consumidor em pontos de recebimento temporário e permanente. As referidas normas preveem que os pontos de recebimento podem ocorrer em diferentes locais, desde que haja responsável técnico pelo procedimento ${ }^{27}$. A ABNT é uma associação civil (privada) para a qual contribuem profissionais com conhecimento técnico, associados ou não. Nas relações civis é o reconhecimento atribuído pelos pares - que utilizam suas publicações como parâmetro - que torna a $\mathrm{ABNT}$ relevante. Entre empresas, ninguém pode ser obrigado a seguir uma norma ABNT, exceto se por liberalidade for convencionado.

Nas relações de consumo, por sua vez, o artigo 39, inciso VIII, do Código de Defesa do Consumidor (CDC) $)^{28}$ veda ao fornecedor de produtos ou serviços colocá-los no mercado sem seguir as especificações previstas em lei e, quando normas específicas não existirem, devem seguir o disposto pela ABNT ou outra entidade credenciada pelo Conselho Nacional de Metrologia, Normalização e Qualidade Industrial (Conmetro).

A ABNT regulou apenas o descarte de medicamentos pelo consumidor, prevendo seu recolhimento em pontos que tenham um responsável técnico (sem

\footnotetext{
${ }^{25}$ A Portaria n. 1.577, de 21 de outubro de 2011, instituiu grupo de trabalho para atualizar a RDC n. 306/2004, porém, a revisão ainda está em andamento. Nenhuma notícia há quanto ao andamento dos trabalhos. AGÊNCIA NACIONAL DE VIGILÂNCIA SANITÁRIA - ANVISA. Portaria n. 1.577, de 21 de outubro de 2011. Disponível em: <bvsms.saude.gov.br/bvs/saudelegis/anvisa/2011/prt1577-21-10-2011.html>. Acesso em: 25 maio 2017.

${ }^{26}$ AGÊNCIA NACIONAL DE VIGILÂNCIA SANITÁRIA - ANVISA. Resolução RDC n. 222, de 28 de março de 2018, cit.

${ }^{27}$ ABNT - ASSOCIAÇÃO BRASILEIRA DE NORMAS TÉCNICAS Norma brasileira ABNT NBR 16457:2016. Logística reversa de medicamentos de uso humano vencido e/ou em desuso - procedimento. Rio de Janeiro: ABNT, 2016.

${ }^{28}$ BRASIL. Lei n. 8. 078, de 11 de setembro de 1990. Dispõe sobre a proteção do consumidor e dá outras providências. Disponível em: <http://www.planalto.gov.br/ccivil_03/Leis/l8078.htm>. Acesso: em 27 mar. 2017.
} 
especificar sua qualificação), podendo o posto de recebimento ser temporário. A ABNT recomenda que as embalagens secundárias e as bulas sejam separadas para reciclagem.

\section{Discussão}

No Ocidente, o consumo de medicamentos está atrelado à noção de tratamento médico e corresponde de $20 \%$ a $30 \%$ do valor global gasto em saúde, constituindo o principal custo em saúde dos orçamentos ${ }^{29}$. Em 2014, na União Europeia, o custo com medicamentos (sem considerar os consumidos nos hospitais) é a terceira maior despesa nos cuidados em saúde e superou os 200 bilhões de euros ${ }^{30}$.

As substâncias que compõem os medicamentos são descartadas na natureza durante o processo de industrialização (dentro dos limites aceitos e permitidos pela tecnologia existente), em seu consumo (o metabolismo humano não as absorve integralmente) e no descarte - a tecnologia para tornar os medicamentos inertes também é poluente, e jogá-los diretamente na natureza ou no lixo doméstico (que não recebe tratamento para torná-las totalmente inertes) também é prejudicial. A despesa com medicamentos, dessa forma, ocorre tanto em sua aquisição quanto em seu descarte, que no Brasil exige emprego de tecnologia mais cara do que o tratamento dado ao lixo doméstico para torná-lo inerte.

Pelo princípio da precaução, presente em todas as questões ambientais, nenhuma substância deveria retornar ao meio ambiente sem prévio tratamento. Se ainda não há tecnologia para garantir o correto descarte, isso deveria significar maior cuidado na produção, na distribuição e no consumo. Permitir o acesso a fármacos e POE deveria ser constantemente reavaliado, seja para diminuir restrições porque há pesquisas demonstrando sua segurança de uso e descarte, seja para substitui-los por outros produtos menos poluentes.

Silva e Collins ${ }^{31}$ apontam que os POE não necessitam ser persistentes para causar efeitos negativos, uma vez que é contínua a entrada desses compostos no meio ambiente devido aos processos industriais, ao descarte e à excreção (metabolizada e não metabolizada) nos esgotos e nos corpos d'água.

No Brasil, ainda conforme as autoras, a principal fonte de contaminação ambiental das águas se dá através de esgotos domésticos não tratados, uma vez que a maioria dos efluentes urbanos não passa pelo processo de tratamento terciário para remoção de nutrientes e desinfecção. Por isso, estudos de degradação de POE são de

\footnotetext{
${ }^{29}$ WORLD HEALTH ORGANIZATION. Health systems financing: the path to universal coverage. The World Health Report 2010. Disponivel em: <http://www.who.int/whr/2010/10_summary_en.pdf?ua=1>. Acesso em: 14 jun. 2017.

${ }^{30}$ ORGANIZATION FOR ECONOMIC COOPERATION AND DEVELOPMENT. Pharmaceuticals. Disponível em: <http://www.oecd.org/els/health-systems/pharmaceuticals.htm>. Acesso em: 05 jun. 2017.

${ }^{31}$ SILVA, C. G. A.; COLLINS, C. H. op. cit., p. 665-676.
} 
extrema importância para avaliar a cinética de transformação desses compostos, bem como estudar quais são os novos compostos formados e sua potencial toxicidade.

Boxall et al. procuraram levantar as principais questões envolvendo a contaminação de medicamentos e produtos de higiene pessoal no meio ambiente. Em relação aos riscos, identificaram que

os riscos desses produtos no meio ambiente variam em cada região geográfica conforme a presença ou ausência de locais de fabricação, o nível de produtos utilizados, demografia, práticas culturais, características do meio ambiente e do clima, potencial de diluição no meio ambiente e infraestrutura relacionada aos tratamentos de esgoto e água potável ${ }^{32}$.

O Brasil possui 5.570 municípios $^{33}$, dos quais 4.567 (82\%) prestaram em 2016 serviços de coleta, tratamento e disposição final de RSS, conforme a Associação Brasileira de Limpeza Pública e Resíduos Especiais ${ }^{34}$. Eventual RSS que não seja descartado corretamente e venha a ser despejado no esgoto doméstico poderá não receber tratamento algum.

Daughton e Ternes relacionam as substâncias ativas encontradas em amostra de água retirada da natureza identificando o medicamento ou produto de higiene pessoal que as possuem em sua fórmula, explicam os riscos e sugerem pesquisas decorrentes de seu estudo. Alertam ainda os autores:

Uma grande questão não abordada sobre a saúde humana são os efeitos no longo prazo da ingestão muito baixa, via água potável, de doses subterapêuticas de numerosos fármacos várias vezes ao dia por muitas décadas. Esta preocupação relaciona-se especialmente com crianças, fetos e pessoas sofrendo de certas deficiências de enzimas (que podem ser induzidas por alimentos, e.g., inibição de oxidase microssonal por suco de toranja) $)^{35}$ (Tradução livre.)

O descarte correto pode prevenir que pessoas adoeçam e ainda gerar economia, tanto pela menor necessidade de medicamentos quanto por facilitar o

${ }^{32}$ BOXALL, A. B. A. et al. Pharmaceuticals and personal care products in the environment: what are the big questions? Environmental Health Perspectives, Research Triangle Park: v. 120, n. 9, p. 1224, 2012. 10.1289/ehp.1104477.

${ }^{33}$ INSTITUTO BRASILEIRO DE GEOGRAFIA E ESTATÍSTICA. Perfil dos municípios brasileiros 2015. [2016]. Disponível em: <http://ibge.gov.br/home/estatistica/economia/perfilmunic/2-15/default.shtm>. Acesso em: 05 jun. 2017.

${ }^{34}$ ASSOCIAÇÃO BRASILEIRA DE EMPRESAS DE LIMPEZA PÚBLICA E RESÍDUOS ESPECIAIS - ABRELPE. Panorama dos Resíduos Sólidos no Brasil. [São Paulo], 2016. Disponível em: <http://www.abrelpe.org.br/ panorama_apresentacao.cfm>. Acesso em: 07 mai. 2017.

${ }^{35}$ DAUGHTON, C. G.; TERNES, T. A. Pharmaceuticals and personal care products in the environment: agents of subtle change? Environmental Health Perspectives, Research Triangle Park, v. 107, Suppl. 6, p. 908, Dec. 1999. 
tratamento da água - embora os aspectos ambiental e econômico não sejam relacionados com frequência, tanto na produção não comercializada quanto no descarte inadequado há um custo (ambiental) socializado.

Em levantamento das fontes de desperdício em unidades do Hospital Universitário da Universidade de São Paulo, Castilho et al. ${ }^{36}$ apontaram que, em quatro unidades, a percepção dos profissionais é de que medicamento é o produto mais desperdiçado; em uma unidade, foi o segundo mais indicado.

Fischer e Freitas ${ }^{37}$ indicam a superprescrição, a automedicação, as amostras grátis e o mau gerenciamento de estoques como as razões para os medicamentos não serem utilizados. Os autores apontam que antibióticos, estrogênios, antineoplásicos e imunossupressores são as substâncias que merecem maior atenção.

O levantamento realizado para este artigo aponta que as pesquisas brasileiras referentes ao descarte de medicamentos são realizadas por pesquisadores de áreas não jurídicas. Partindo da interpretação literal de normas administrativas da Anvisa e do Conama, tais pesquisadores fazem diagnóstico da presença de medicamentos nos lares, do comportamento dos pacientes quanto a seu descarte e da conformidade do comportamento dos trabalhadores de estabelecimentos de saúde quanto ao previsto em seus planos de gerenciamento de resíduos de saúde e na legislação sanitária.

O Plano de Gerenciamento de Resíduo Sólido (PGRS) é documento redigido pelo profissional responsável técnico de cada estabelecimento gerador de resíduo, e seu conteúdo mínimo está previsto no artigo 21 da PNRS. Nos estabelecimentos geradores de resíduo de serviços de saúde, o PGRS chama-se Plano de Gerenciamento de Resíduos de Serviços de Saúde (PGRSS), que está previsto como documento obrigatório nos quatro atos normativos indicados no item III. Descarte de medicamentos na legislação federal. É o responsável técnico de cada estabelecimento de saúde que definirá, no PGRSS, a forma como se dará o descarte.

A RDC n. 306/2004 detalha o conteúdo do PGRSS. Em linhas gerais, seguindo padrões de segurança estabelecidos para as instalações físicas e treinamento de funcionários, deve ser mapeado o fluxo de todos os resíduos gerados. Procedimentos não previstos na legislação, mas que venham a ser utilizados por uma atualização tecnológica, por exemplo, podem ser incluídos no PGRSS. A proibição é ter rotina diversa ao retratado (item 13.2.3).

\footnotetext{
${ }^{36} \mathrm{CASTILHO}, \mathrm{V}$ et al. Levantamento das principais fontes de desperdício de unidades assistenciais de um hospital universitário. Revista da Escola de Enfermagem da USP, São Paulo, v. 45, n. esp., p. 1613-1620, 2011. Disponível em: <http://www.scielo.br/readcube/epdf.php?doi=10.1590/S008062342011000700012\&pid=S0080-62342011000700012\&pdf_path=reeusp/v45nspe/v45nspea12. pdf\&lang=pt>. http://dx.doi.org/10.1590/S0080-62342011000700012.

${ }^{37}$ FISCHER, M. I; FREITAS, G. R. M. Pizzol, T. S. D. P; SEIXAS, L. J (Rev.). Descarte de medicamentos. Boletim Informativo do CIM-RS, Porto Alegre, n. 2, mai. 2011. Disponível em: <www.ufrgs.br/boletimcimrs>. Acesso em: nov. 2013.
} 
A comparação entre os requisitos previstos para o PGRS na PNRS e para o PGRSS na RDC n. 306/2004 permite identificar que há ênfase na PNRS para a integração entre diferentes PGRS e estabelecimento de metas e ações preventivas, enquanto o PGRSS exigido pela Anvisa tem a função de monitoramento e é mais descritivo, com controle de indicadores, mas apresentando a reciclagem como possibilidade para o Grupo B ou D, e não obrigação (contrariando a legislação federal).

Os requisitos mínimos exigidos para o PGRS pela PNRS devem estar contemplados em todos os PGRSS. O PGRSS é documento integrante do processo de licenciamento ambiental, baseado nos princípios de proteção à saúde pública e ao meio ambiente e da não geração e minimização de RSS, devendo apontar e descrever as ações relativas ao manejo, geração, segregação, acondicionamento, coleta, armazenamento, transporte, reciclagem, tratamento e disposição final. Esta definição de PGRSS está em conformidade com a PNRS, a Resolução Conama n. 358/2005 e a RDC n. 222/2018.

A PNRS é omissa quanto à qualificação de quem elabora o plano de gerenciamento de resíduo sólido. Conama e Anvisa exigem que o profissional responsável pela elaboração do PGRSS esteja habilitado por seu conselho de classe, com apresentação de documento constando a responsabilidade técnica. O Conama exige, ainda, que o profissional tenha nível superior.

É a qualificação do profissional que fará a diferença, pois o que lhe será exigido é a apresentação de um PGRSS cujo conteúdo é discricionariedade do profissional. A utilização de texto já aprovado para outro estabelecimento de saúde pode parecer uma alternativa simples para obtenção de licenças, porém o PGRSS tem a sua importância e precisa ser redigido após processo de análise do caso concreto.

As regras de descarte de medicamentos vencidos ou não usados podem variar conforme o município, tendo em vista que proteger o meio ambiente e combater a poluç̧ão em qualquer de suas formas é competência comum da União, dos estados e dos municípios, nos termos do artigo 22, inciso II da CF/1988. Sempre que houver omissão da União e do Estado - o que é previsível em assuntos complexos que precisam ser adaptados a diferentes realidades -, cabe ao Município estabelecer as regras, como ocorre no recolhimento dos medicamentos vencidos ou não usados que são descartados, o que exige atualização do responsável técnico quanto às exigências locais pela ausência de padronização.

Conforme dito anteriormente, a PNRS prevê a integração entre PGRS - e se alguma instituição ou estabelecimento comercial vier a ser um ponto de coleta de medicamento, mesmo que temporariamente, terá de ter seu PGRSS. As diferentes realidades encontradas no Brasil justificam a flexibilidade que é dada para o responsável técnico adequar-se $\mathrm{s}^{38}$.

${ }^{38} \mathrm{~A}$ RDC n. 222/2018, em seu artigo $8^{\circ}$, prevê que o estabelecimento terá PGRSS único, mesmo que possua licenças sanitárias individualizadas por serviços. 
Em relação aos medicamentos, contrastando com os estudos apresentados até o momento, a redação da RDC n. 306/2004 prevê que

Resíduos no estado líquido podem ser lançados na rede coletora de esgoto ou em corpo receptor, desde que atendam respectivamente às diretrizes estabelecidas pelos órgãos ambientais, gestores de recursos hídricos e de saneamento competentes ${ }^{39}$.

Já a regulamentação ambiental apresenta a seguinte orientação:

Art. 11 Os efluentes líquidos provenientes dos estabelecimentos prestadores de serviços de saúde, para serem lançados na rede pública de esgoto ou em corpo receptor, devem atender às diretrizes estabelecidas pelos órgãos ambientais, gestores de recursos hídricos e de saneamento competentes ${ }^{40}$.

Os princípios ativos encontrados nos medicamentos e POE contaminam solo e água em qualquer forma de administração. Se não contaminassem na forma líquida, também não contaminariam na forma sólida e não teriam sentido as preocupações com logística reversa, por exemplo. Todas as pesquisas encontradas demonstram o contrário: que o cuidado empregado no descarte dos medicamentos na forma líquida deve ser o mesmo dado a comprimidos e pílulas.

A RDC n. 222/2018 estabelece regras distintas aos RSS do Grupo B que tenham características de periculosidade: se o RSS estiver em estado líquido, deve ser tratado antes da disposição final ambientalmente adequada e, se estiver no estado sólido, deve ser disposto em aterro de resíduos perigosos - Classe I (artigos 57 e 58).

Dessa forma, mesmo que todos os funcionários conheçam e apliquem o PGRSS, caso tenha sido escrito exclusivamente a partir das exigências da Anvisa e do Conama - sem considerar a obrigação de reduzir a geração de resíduos -, a legislação federal estará sendo descumprida. Atos normativos como as resoluções da Anvisa e do Conama têm força de lei sempre que o legislador for omisso. A publicação da PNRS e do Decreto n. 7.404/2010 ${ }^{41}$ não revogou expressamente a RDC n. 306/2004, porém, sempre que houver incompatibilidade entre os textos, a PNRS prevalecerá. $\mathrm{O}$ ato administrativo precisa adequar-se à lei, não o contrário.

A divergência entre o conteúdo da RDC n. 306/2004 e da legislação federal deveria fazer com que os responsáveis técnicos, ao elaborar o PGRSS, não

\footnotetext{
${ }^{39}$ AGÊNCIA NACIONAL DE VIGILÂNCIA SANITÁRIA - ANVISA. Resolução RDC n. 306, de 10 de dezembro de 2004, cit. ${ }^{40}$ BRASIL. CONSELHO NACIONAL DO MEIO AMBIENTE - CONAMA. Resolução n. 358, de 29 de abril de 2005, cit. ${ }^{41}$ BRASIL. Decreto $n^{\circ} 7.404$, de 23 de dezembro de 2010. Regulamenta a Lei no 12.305, de 2 de agosto de 2010, que institui a Política Nacional de Resíduos Sólidos, cria o Comitê Interministerial da Política Nacional de Resíduos Sólidos e o Comitê Orientador para a Implantação dos Sistemas de Logística Reversa, e dá outras providências. Disponível em: < http://www.planalto.gov.br/ccivil_03/_ato2007- 2010/2010/ decreto/d7404.htm>. Acesso em: 07 maio 2017.
} 
considerassem a possibilidade de descarte na rede coletora de esgoto. Igual procedimento deve ser considerado na vigência da RDC n. 222/2018 quando houver omissão. Reitera-se que o Brasil está vinculado ao tratado internacional em que há o reconhecimento de que

Os riscos potenciais de determinados tipos de resíduos ainda não foram completamente documentados; não existem testes para definir quantitativamente esses riscos. É necessário aprofundar as pesquisas a fim de desenvolver meios para caracterizar riscos desses resíduos em relação ao ser humano e/ou ao meio ambiente ${ }^{42}$.

Aliado ao compromisso internacional, há o princípio da precaução, em que os danos precisam ser evitados. É inevitável que ocorra o descarte do medicamento utilizado e não metabolizado pelo paciente na rede coletora de esgoto, mas isso não pode ser interpretado como a via correta do produto embalado e sem serventia. $\mathrm{O}$ destino correto do produto não utilizado deverá estar em conformidade com os sistemas locais de coleta, e não pode ser a rede de esgoto.

É papel do responsável técnico ter conhecimento atualizado de sua expertise profissional e aplicá-lo em detrimento de leis com entendimentos ultrapassados e é urgente que haja atualização dessas normas pelo passivo ambiental devido ao prejuízo que apresentam à saúde. A RDC n. 222/2018 revogou os dispositivos da RDC n. 306/2004 que eram contrários à legislação federal, porém sem indicar o procedimento adequado.

Também deve-se levar em conta que regras difíceis de cumprir e custos elevados incentivam o abandono de resíduos de serviços de saúde em áreas remotas ou sua mistura com o lixo comum. O PGRSS bem feito, por sua vez, permite a identificação e melhor segregação de resíduos - não é por acaso que a ABNT sugere que as embalagens secundárias e as bulas, feitas de papel, sejam separadas dos medicamentos em si antes do descarte.

A disposição final adequada dos medicamentos pode mudar à medida que a tecnologia avança. Martini ${ }^{43}$, em relação aos resíduos classificados como grupo A ou grupo E e descartados na cidade de São Paulo, estudou a alternativa da valorização energética desses resíduos pós-tratados e, pela composição gravimétrica, identificou a presença de materiais de alto poder energético, o que tornaria viável a aplicação das tecnologias de coprocessamento, incineração, plasma, pirólise e gasificação para valorização energética de resíduos A e E.

\footnotetext{
${ }^{42}$ BRASIL. Decreto n. 875, de 19 de julho de 1993, cit.

${ }^{43}$ MARTINI, A. A. Estudo de alternativa de valorização de resíduos de serviços de saúde advindos de processo de desinfecção por desativação eletrotérmica (ETD). 2016. Dissertação (Mestrado) - Faculdade de Saúde Pública, Universidade de São Paulo, São Paulo, 2016.
} 
Sora ${ }^{44}$ avaliou a capacidade de valorização energética nos países da União Europeia. A legislação da União Europeia equipara a transformação de resíduo em energia à reciclagem, o que desestimula a efetiva reciclagem com reaproveitamento de materiais em fins mais nobres. Além disso, as plantas de incineração estão sendo construídas de forma concentrada no território - e o impacto ambiental das longas distâncias percorridas pelos resíduos talvez não compense, sob o ponto de vista ambiental, que haja esse fluxo.

É provável que a incineração de medicamentos seja substituída por técnicas menos poluentes. Na Universidade Federal de Minas Gerais (UFMG), tecnologia baseada em processos oxidativos (Fenton e focatálise) estão sendo testados como tratamento químico aos medicamentos, que passariam a formar estruturas moleculares mais biodegradáveis, destruindo os princípios ativos ambientalmente agressivos ${ }^{45}$.

A empresa Veolia, gestora de resíduos, conseguiu recuperar de medicamentos obsoletos uma quantidade de platina suficiente para fabricar um par de brincos, avaliado em 1.200 libras esterlinas ${ }^{4647}$.

\section{Considerações finais}

Impedir que o medicamento sem serventia entre em contato direto com a natureza é um grande desafio. Enquanto houver produção do que não será comprado e compra do que não será usado, a mitigação de danos ambientais, sociais e econômicos deve ser feita com o descarte correto.

O princípio da precaução, aplicado ao meio ambiente no sentido de evitar poluir, já seria suficiente para que qualquer produto químico - principalmente os não utilizados - não pudesse ter como destino direto a natureza. É uma questão de bom senso que precisa ser cultivada nos profissionais e na população. A qualidade da água é essencial para a qualidade de vida de todos os seres vivos.

Avanços da tecnologia devem ser considerados na formulação e na revisão de rotinas de descarte. Também é importante compreender e divulgar os fatores que levam à adoção dos procedimentos, informação que auxilia os revisores do que está implementado.

\footnotetext{
${ }^{44}$ SORA, M. J. Incineration overcapacity and waste shipping in Europe: the end of the proximity principle? [Barcelona]: Fundació ENT, 2013. Disponível em: <www.ent.cat>. Acesso em: 07 mai. 2017.

${ }^{45}$ TECNOLOGIA pode substituir incineração de medicamentos e favorecer a reciclagem de material descartado. Universidade Federal de Minas Gerais, Agência de Notícias, Belo Horizonte, 8 abr. 2010. Disponível em: <https://www.ufmg.br/online/arquivos/015078.shtml>. Acesso em: 30 abr. 2017.

${ }^{46}$ VEOLIA. Lord of the recycled rings. 2 Nov. 2016. Disponível em: <http://www.veolia.co.uk/media/media/ lord-recycled-rings>. Acesso em: 14 dez. 2016.

${ }^{47}$ REINTJES, M. Veolia mining pharmaceutical's hidden treasures. Recycling International, [Arnhem], 2016. Disponível em <http://www.recyclinginternational.com>. Acesso em: 11 nov. 2016.
} 
Não há princípio ativo de medicamento sem risco: este é o entendimento declarado pelo Brasil e por outros países há anos, inclusive antes da publicação da RDC n. 306/2004 e da Resolução Conama n. 258/2005. Independentemente da norma em vigor, à Anvisa foi delegada a regulamentação de RSS, porém fazê-lo de forma contrária à legislação federal extrapola sua competência. Mesmo raciocínio é aplicado ao Conama.

Entre os objetivos da PNRS, estão a não geração, a redução, a reutilização, a reciclagem, o tratamento e a disposição final ambientalmente adequada dos rejeitos - os medicamentos não estão fora desta regra. As regulamentações da Anvisa são atos administrativos com força de lei quando há omissão do legislador, de forma que não podem contrariar a PNRS.

Se na prática os estabelecimentos de saúde são fiscalizados por profissionais da vigilância sanitária, que restringem a conferência às regras sanitárias - ou seja, se há PGRSS, e não a aplicação de procedimentos em conformidade com a ciência e as tecnologias mais recentes -, tal fato não pode ser utilizado pelos profissionais para negligenciar suas decisões na função de responsáveis técnicos. Uma vez gerado o passivo ambiental, a empresa para a qual trabalham será responsabilizada.

A falta de padronização de procedimentos dificulta sua divulgação e fiscalização. Houvesse um posicionamento claro e uma padronização mínima, a informação e a consequente educação das pessoas de como descartar corretamente poderia ser divulgada durante o consumo, fazendo constar nas embalagens regras quanto ao descarte, por exemplo.

\section{Referências}

ABNT - ASSOCIAÇÃO BRASILEIRA DE NORMAS TÉCNICAS Norma brasileira ABNT NBR 16457:2016. Logística reversa de medicamentos de uso humano vencido e/ou em desuso - procedimento. Rio de Janeiro: ABNT, 2016.

Norma brasileira ABNT NBR 10004:2004. Resíduos sólidos - classificação. Rio de Janeiro: ABNT, 2004.

ABRELPE - ASSOCIAÇÃO BRASILEIRA DE EMPRESAS DE LIMPEZA PÚBLICA E RESÍDUOS ESPECIAIS. Panorama dos Resíduos Sólidos no Brasil. [São Paulo], 2016. Disponível em: <http://www.abrelpe.org.br/panorama_apresentacao.cfm>. Acesso em: 07 mai. 2017.

BELLAN, N. et al. Critical analysis of the regulations regarding the disposal of medication waste. Brazilian Journal of Pharmaceutical Sciences. São Paulo, v. 48, n. 3, p. 507-513, July/ Sept. 2012. Disponível em: <http://www.scielo.br/pdf/bjps/v48n3/a18v48n3.pdf>. http:// dx.doi.org/10.1590/S1984-82502012000300018. 
BOXALL, A. B. A. et al. Pharmaceuticals and personal care products in the environment: what are the big questions? Environmental Health Perspectives, Research Triangle Park: v. 120, n. 9, p. 1221-1229, 2012. 10.1289/ehp.1104477.

BRASIL. SECRETARIA DE RECURSOS HÍDRICOS E AMBIENTE URBANO. Edital de chamamento para implantação de sistema de logística reversa. Diário Oficial da União Seção 3, Brasília, 10 out 2013, n. 197.

CASTILHO, $\mathrm{V}$ et al. Levantamento das principais fontes de desperdício de unidades assistenciais de um hospital universitário. Revista da Escola de Enfermagem da USP, São Paulo, v. 45, n. esp., p. 1613-1620, 2011. Disponível em: <http://www.scielo.br/readcube/ epdf.php?doi=10.1590/S0080-62342011000700012\&pid=S0080-62342011000700012\&pdf_ path=reeusp/v45nspe/v45nspea12.pdf\&lang=pt $>$. http://dx.doi.org/10.1590/S008062342011000700012 .

DAUGHTON, C. G.; TERNES, T. A. Pharmaceuticals and personal care products in the environment: agents of subtle change? Environmental Health Perspectives, Research Triangle Park, v. 107, Suppl. 6, Dec. 1999.

FISCHER, M. I; FREITAS, G. R. M. Pizzol, T. S. D. P; SEIXAS, L. J (Rev.). Descarte de medicamentos. Boletim Informativo do CIM-RS, Porto Alegre, n. 2, mai. 2011. Disponível em: <www.ufrgs.br/boletimcimrs >. Acesso em: nov. 2013.

GIL, A. C. Métodos e técnicas de pesquisa social. São Paulo: Atlas, 2007.

INSTITUTO BRASILEIRO DE GEOGRAFIA E ESTATÍSTICA. Perfil dos municípios brasileiros 2015. [2016]. Disponível em: <http://ibge.gov.br/home/estatistica/economia/ perfilmunic/2-15/default.shtm>. Acesso em: 05 jun. 2017.

MARCONI, M. A., LAKATOS, E. M. Fundamentos de metodologia científica. 6. ed. São Paulo: Atlas, 2009.

MARTINI, A. A. Estudo de alternativa de valorização de resíduos de serviços de saúde advindos de processo de desinfecção por desativação eletrotérmica (ETD). 2016. Dissertação (Mestrado) Faculdade de Saúde Pública, Universidade de São Paulo, São Paulo, 2016.

ORGANIZATION FOR ECONOMIC COOPERATION AND DEVELOPMENT. Pharmaceuticals. Disponível em: $<$ http://www.oecd.org/els/health-systems/pharmaceuticals. htm>. Acesso em: 05 jun. 2017.

REINTJES, M. Veolia mining pharmaceutical's hidden treasures. Recycling International, [Arnhem], 2016. Disponível em <http://www.recyclinginternational.com>. Acesso em: 11 nov. 2016.

SILVA, C. G. A.; COLLINS, C. H. Aplicações de cromatografia líquida de alta eficiência para o estudo de poluentes orgânicos emergentes. Química Nova, Campinas, v. 34, n. 4, p. 665-676, 2011. Disponível em: <http://unicamp.sibi.usp.br/unicamp/bitstream/handle/ SBURI/23903/S0100-40422011000400020.pdf? sequence=1>. Acesso em: 01 mar. 17. http:// dx.doi.org/10.1590/S0100-40422011000400020. 
SORA, M. J. Incineration overcapacity and waste shipping in Europe: the end of the proximity principle? [Barcelona]: Fundació ENT, 2013. Disponível em: <www.ent.cat>. Acesso em: 07 mai. 2017.

TECNOLOGIA pode substituir incineração de medicamentos e favorecer a reciclagem de material descartado. Universidade Federal de Minas Gerais, Agência de Notícias, Belo Horizonte, 8 abr. 2010. Disponível em: <https://www.ufmg.br/online/arquivos/015078. shtml>. Acesso em: 30 abr. 2017.

VEOLIA. Lord of the recycled rings. 2 Nov. 2016. Disponível em: <http://www.veolia.co.uk/ media/media/lord-recycled-rings $>$. Acesso em: 14 dez. 2016.

WORLD HEALTH ORGANIZATION. Health systems financing: the path to universal coverage. The World Health Report 2010. Disponível em: <http://www.who.int/whr/2010/10_ summary_en.pdf?ua=1>. Acesso em: 14 jun. 2017.

Giselle Margareth Pilla Blankenstein - Doutora em Ciências pela Faculdade de Saúde Pública da Universidade de São Paulo (FSP/USP) e bolsista Capes no Programa de Saúde Global e Sustentabilidade da FSP/USP; mestre em Direito pela Pontifícia Universidade Católica de São Paulo. Advogada. São Paulo/SP, Brasil. E-mail: gmblankenstein@usp.br

Arlindo Philippi Junior - Livre Docente em Política e Gestão Ambiental pela Universidade de São Paulo (USP); pós-doutor em Estudos Urbanos e Regionais pelo Massachussetts Institute of Technology (Estados Unidos); doutor em Saúde Pública pela USP. Professor Titular da USP; chefe do Departamento de Saúde Ambiental da Faculdade de Saúde Pública da USP. Membro do Conselho Deliberativo do Interdisciplinarity Investigation Center on Climate Change (Incline) da USP. São Paulo/SP, Brasil. 